\title{
Report
}

\section{Prevalence and Characterization of Putative Oligotrophic Bacteria in Fayoum Soils, Egypt}

\author{
Sayed Abdelaziz ${ }^{1,}$, Khaled Elbanna ${ }^{1,2}$, Rabee Elshahawy ${ }^{1}$ \\ ${ }^{1}$ Department of Agricultural Microbiology, Faculty of Agriculture, Fayoum University, Fayuom, Egypt \\ ${ }^{2}$ Department of Biology, Faculty of Applied Sciences, Umm Al-Qura University, Makkah, Kingdom of Saudi Arabia \\ Email address: \\ sa171@fayoum.edu.eg (S. Abdelaziz), kab00@fayoum.edu.eg (K. Elbanna), ssazeem@gmail.com (R. Elshahawy) \\ ${ }^{*}$ Corresponding author
}

\section{To cite this article:}

Sayed Abdelaziz, Khaled Elbanna, Rabee Elshahawy. Prevalence and Characterization of Putative Oligotrophic Bacteria in Fayoum Soils, Egypt. Frontiers in Environmental Microbiology. Vol. 2, No. 2, 2016, pp. 6-11. doi: 10.11648/j.fem.20160202.11

Received: May 16, 2016; Accepted: June 22, 2016; Published: September 18, 2016

\begin{abstract}
A variety of microbes can inhabit in extreme conditions. Extreme is a relative term which is viewed compared to what is normal for human beings. These microorganisms are known as oligotrophs. This work aimed to benefit from such organisms isolated from poor soils prevailing in fayoum Governorate. A survey of these organisms (specially) olignitrotrophs and oligocarbotrophs) was made on different soil samples. One hundred and twelve isolates were obtained from eight different soil sites. Ninety eight were obtained from NB/1000 (NB= nutrient broth) and fourteen from NB/10000 dilution. Fixed counts of the different isolates, when inoculated in NB medium with its different dilutions, were almost of constant counts for 30 days incubation at $30^{\circ} \mathrm{C}$ proved to be facultative not obligate oligotrophs. Eleven isolates produce IAA in amounts averaged $15 \mu \mathrm{g} / \mathrm{ml}$ and the rest were below $15 \mu \mathrm{g} / \mathrm{ml}$. Five isolates only were capable to produce salyselic acids (S.A.) in appreciable amounts (> $100 \mu \mathrm{g} / \mathrm{ml}$ ) and the rest was below $100 \mu \mathrm{g} / \mathrm{ml}$. fifty four isolates solubilized zink (>10 mm clear zone), and the rest was below 5 $\mathrm{mm}$ halo zone. Nine isolates solubilize phosphate $(10 \mathrm{~mm}$ clear zone) and the rest was below $5 \mathrm{~mm}$ diameter. Fourty-seven isolates were able to fix nitrogen (olignitrotrophic) in medium deprived completely of $\mathrm{N}$-source. Seventeen isolates were $\mathrm{G}^{-}$and the rest was $\mathrm{G}^{+}$. All isolates were oxidase and catalase positive but cannot ferment lactose. Most isolates were motile (95.5\%), spore formers $(76.6 \%)$ and all were short or long rods. Cellulase enzyme produced by seventeen and chitinase by five isolates only. All isolates examined were facultative oligotrophs as they grew on silica gel NB medium deprived of any source of carbon as well as on complete NB medium.
\end{abstract}

Keywords: Oligotrophs, Oligonitrotrophs, Oligocarbotrophs, Extremophiles, Putative $\mathrm{N}_{2}$-fixers, Biocontrol Agents

\section{Introduction}

Moderate environments are important to sustain normal microbial life. Moderate means environments with $\mathrm{pH}$ near neutral, temperature around $28-30^{\circ} \mathrm{C}$, appropriate amounts of carbon, nitrogen and other nutrients, available water, aeriation ... etc. Any environmental conditions that can be perceived as beyond the normal acceptable range, is an extreme conditions. Soils is a heterogeneous medium of solids, liquids, organic and gaseous phases varying in its proportions. Therefore, a large number of microorganisms live and survive with difficulty in soil because of the non availability and low rate of nutrients supply. It may be advantageous for soil microorganisms to have capability of growing in low nutrients condition. Microorganisms possessing this capability are called "oligotrophic" [1-4]. Most soils can be regarded as being oligotrophs because they are generally considered to contain insufficient carbon to allow the continuous growth of microorganisms. The paucity of biologically available nutrients in soil imposes constraints on microorganisms growth and productivity of higher trophic levels [5]. A variety of microbes however, survive and grow in such environments, and are known as extremophiles, not only tolerate specific extreme conditions, but usually require these for survival and growth ([6-9]. Many of these bacteria can be defined as obligate oligotrophs because they are unable to grow in carbon 
rich medium [4]. A number of putative oligotrophic bacteria believed to be able to obtain atmospheric nitrogen wheather via $\mathrm{N}_{2}$-ase enzyme or by scavenging it from the surrounding [10-12].

Conseqantly, the intended objective of the present work is to study the possible prevalence of the oligotrophic bacteria in various soils of Fayoum governorate, enumeration of their counts, isolation of some individuals and studying some of their characters and activities (phosphate and zink solubilization, $\mathrm{N}_{2}$-fixation, catalase and peroxidase enzyme activities, siderophores, salysilic acid and IAA production. In addition to determine some morphological characters of these isolates. The capability, of such isolates in controlling some plant pathogenic fungi (in vitro) was also determined. The resistibility of these isolates to some adverse conditions prevailing in our conditions ( $\mathrm{pH}$, temp. and salt content) were also included.

\section{Materials and Methods}

\subsection{Survey of the Putative Oligotrophic Bacteria in Fayoum Soils}

A preliminary survey for facultative and/or obligate oligotrophic bacteria in fayoum soils was undertaken using nutrient and diluted nutrient broth medium (NB and DNB media). The full strength of conventional nutrient broth medium contained $1 \%(\mathrm{w} / \mathrm{v})$ each of beef extract (Difco) and trypticase peptone, $0.5 \%(\mathrm{w} / \mathrm{v}) \mathrm{NaCl}$ in deionized water was used. In all steps of work, the NB and DNB media were sterilized at $121^{\circ} \mathrm{C}$ for 20 minutes and the $\mathrm{pH}$ was adjusted to 7.2. The dilutions used were from $10^{-1}$ to $10^{-6}$, one ml aliquots of soils suspensions from each dilution was placed and spread in Petri dishes containing nutrient agar medium. The original medium (NB) was provided with $2 \%$ agar (Difco) for isolation and enumeration of bacteria. The diluted NB i.e NB/10, $\mathrm{NB} / 100, \mathrm{NB} / 1000$ and $\mathrm{NB} / 10000$ were incubated at $30^{\circ} \mathrm{C}$ for ten days and C.F.U. were daily determined. It is of interest to mention that when high grade agar is not available (Noble...etc), repeat washing of low grade one can be used successfully. Different isolates were also selected from previously mentioned plates. In case of counting the putative oligotrophic bacteria in liquid media (NB), the bacterial growth was observed visually after one or two weeks at $30^{\circ} \mathrm{C}$. And the optical density was determined using the standard barium sulphate suspension method described by Baron et al., [13]. For this determination a loopfull of the 15 days growing isolates which approximately equal to $0.01 \mathrm{ml}$ was taken and inoculated in new NB tubes medium with its dilutions $(\mathrm{NB} / 10$, tell $\mathrm{NB} / 10000)$. After incubation at $30^{\circ} \mathrm{C}$ for 15 days the optical density of each tube was recorded and then the counts were calculated. Worth mentioning that 0.01 bacterial suspension after 15 days incubation was equal to 0.5 McFrland standard solution.

\subsection{Soils Samples Used in This Study}

Eight soil samples were collected from different sites located allover Fayoum governorate distinguished by extreme, harsh and bad environments.

Table 1. Represent the most available characters of the soils.

\begin{tabular}{|c|c|c|c|c|c|c|}
\hline \multirow{2}{*}{ Soil sample No } & \multirow{2}{*}{ Organic C\% } & \multirow{2}{*}{ T.S.S. (1: 2.5$) \%$} & \multicolumn{4}{|c|}{ T, count of bacteria (C.F.U $\mathrm{g}^{-1}$ soil oven dry } \\
\hline & & & NB $\left(\times 10^{4}\right)$ & 100 fold $x 10^{3}$ & 1000 fold $\times 10$ & Soil texture \\
\hline 1 & 0.15 & 1.06 & 7.35 & 39.0 & 6.7 & Clay loam \\
\hline 2 & 0.21 & 10.20 & 4.20 & 6.20 & 3.2 & Sand \\
\hline 3 & 0.19 & 3.06 & 6.30 & 6.70 & 5.4 & Sand \\
\hline 4 & 0.32 & 1.06 & 35.0 & 50.0 & 8.1 & Sand clay \\
\hline 5 & 0.17 & 4.50 & 35.0 & 50.0 & 7.4 & Clay \\
\hline 6 & 0.13 & 15.20 & 5.5 & 6.5 & 6.8 & Clay \\
\hline 8 & 0.34 & 5.20 & 39.0 & 52.0 & 6.0 & Sandy loam \\
\hline
\end{tabular}

\subsection{Morphological, Physiological and Biochemical Characters of Oligotrophic Isolates}

Different morphological characters of isolates obtained were observed on NB and DNB agar media incubated for two weeks at $30^{\circ} \mathrm{C}$ (ANB and ADNB). Cell shape was examined microscopically using gram stain in addition to sporioalation and motility.

The production of acids from selected sugars, solubilization of phosphate [14], Zink [15], were carried out. The capability to produce plant growth promoting substances (PGPs) such as indoleacitic acid (IAA) [16], salyselic acid [17], cellulase production [18], chitinase production [19], and $\mathrm{N}_{2}$-fixation ability [20].

Antifungal activity (potency) of the selected isolates were tested against three plant pathogenic fungi using: Pythium ultimum, Rhizoctonia solani and Fusarium oxysporum in dual culture test [21]. The isolates were grown in NB/1000 in flasks $50 \mathrm{ml}$ aliquot of the medium for about 10 days at $30^{\circ} \mathrm{C}$. Five $\mu \mathrm{l}$ of exponentially growing bacterial culture was streaked along two opposite sides of surface-dried potato dextrose agar (PDA) plates Plates subsequently incubated at $30^{\circ} \mathrm{C}$ for $24 \mathrm{hr}$ following bacterial growth, mycelial ager plug of $5 \mathrm{~mm}$-diameter from a 5 day old culture from the target fungi grown on PDA plate was placed in center of the plate between the two parallel streaks of the test bacteria. Plates inoculated with target fungi alone served as control. All plates were incubated at $30^{\circ} \mathrm{C}$ for 5 days, and then antagonistic activity was assessed by relating diameter on plats inoculated with bacteria to mycelial diameter on control plates and computing percentage inhibition.

Silica gel plates were prepared as described by [22], for the isolation of bacteria to ensure their oligoitrophic nature. 


\section{Results and Discussion}

\subsection{Survey of the Putative Oligotrophic Bacteria in Fayoum Soils}

The term oligotrophy was first defined by marine and fresh water environmental microbiologists to describe microorganisms in ecosystems containing only small amounts of low energy substrates. Almost all fresh and marine water contain only very small amounts of dissolved organic carbon compared with that in conventional laboratory media. Soil is an oligotrophic environment, because much of the organic material which entire the soil has already been partially exploited and, as a consequence, readily assimilable substrates have been removed.

Table (1) illustrates the available characters of the eight samples collected from various locations distinguished by very drastic conditions. Out of the eight soil samples collected, three had very high concentration of salts $(10 \%)$, while three contained high salt $>3$ and $<5.5 \%$ ), and the rest contained less than $1.06 \%$; The organic carbon content of the different soil samples were low $(0.13-0.34 \%)$. Soil texture classes of all samples were diversed between sand and clay as described in Table (1). It was very clear from previous characters that these soils are in very poor and severe conditions. As to microbial densities, the total microbial counts in NBA (nutrient broth Agar), NBA/10, NBA/100, NBA/1000 and NBA/10000, gave decreased figures. Non of all soil samples gave counts $\left(\mathrm{CFU} / \mathrm{g}^{-1}\right)$ increases as the dilution factor increases. The $\mathrm{CFU}$ in NBA was always more than in NBA/100 or NBA/1000) in all soil samples examined. This finding is absolutely contradict with what found by [23], who stated that, NB medium always gave less counts than its 100-fold soil dilutions. The authors added that some components of the NB medium may be detrimental. They also added that oilgotrophic bacterial counts can be estimated as the difference between counts of DNB and NB. Also the oligotrophic bacterial counts were found by Hashimoto et al., [3], when enumerated by a 100 -fold dilution of $\mathrm{NB}^{-}$, was two to three order of magnitude greater than NB-medium. Generally, soil samples tested gave low microbial counts as cfu which were from 4.2 to $39.0 \times 10^{4} / \mathrm{g}^{-1}$.

The kind of agar used as solidifying agent may interfere in the phenomenon of oligotrophy, because it fortified the medium by additional amounts of soluble organic carbon. Washed commercial agar (with distilled water), M\&D, Gigo, Difco and Winlab contained 0.015, 0.06, 0.03, 0024, 0.15 and 0.021 soluble organic carbon, respectively. Most authors neglected the soluble organic carbon which may be present in most types of agar. While Al-Falih [24], used 1.5\% (w/v) purified agar (oxoid) in counting oligotrophic bacteria which gave reasonable counts. Schut et al., [1], stated that many of so-called oligotrophs isolated on agar media, the agar itself, however, contains several hundred mg of utilizable agar and amino acids.

\subsection{Isolatation of Putative Oligotrophs and Determination of Their Characters}

One hundred and twelve bacterial isolates were obtained from eight soils samples which inoculated on 1000 and 10.000 -fold dilutions of NB medium. Ninety eight isolates were obtained from the first dilution and fourteen isolates from the second dilution. The possible morphological and physiological characters of the isolates are summarized in Table (2). Worth mentioning that all isolates were oxidase and catalase positive, non-lactose fermenters, short and long rods, and all were found to be facultative oligotrophs as they grew well on NB and DNB (Diluted NB). All isolates were cultivated on liquid medium (NB) and its dilutions (DNB). The plate method with NBA medium was employed (full strength NA). In addition, all pure isolates were inoculated, at fixed number or counts in NB and its dilutions $(\mathrm{NB} / 10$ to $\mathrm{NB} / 10000$ ). After appropriate incubation time and temperature, the optical density of tubes were recorded and the estimates obtained were translated to counts. In this study, all organisms were in pure cultures, while the phenomenon of oligotrophy was described by the most authors in mixed culture. The diluted NB counts obtained were slightly less than the original (initial) counts. The NB counts were near $10^{6}$ to $10^{7}$ cell $/ \mathrm{ml}$, while the corresponding $\mathrm{NB} / 10000$ were between $10^{5}$ to $10^{6} \mathrm{cell} / \mathrm{ml}$.

Table 2. Some morphological and physiological characters of the 112 putative oligotrophic isolates obtained from eight soil samples collected.

\begin{tabular}{lllllllllllll}
\hline Soil No. & NO. of isolates & IAA & SA & Zns & P.S. & P.N.F & cellulase & chitinase & Sporulation (+) & Motility (+) & G stain (+) \\
\hline 1 & 13 & 11 & 9 & 11 & 11 & 6 & 3 & 1 & 11 & 13 & 11 \\
2 & 7 & 3 & 3 & 4 & 4 & 3 & 1 & 1 & 6 & 7 & 6 \\
3 & 10 & 6 & 8 & 6 & 6 & 3 & 3 & 0 & 7 & 8 & 8 \\
4 & 37 & 15 & 11 & 16 & 14 & 16 & 7 & 3 & 27 & 34 & 32 \\
5 & 12 & 9 & 3 & 6 & 6 & 4 & 2 & 1 & 11 & 12 & 11 \\
6 & 11 & 2 & 1 & 3 & 3 & 4 & 1 & 1 & 9 & 11 & 11 \\
7 & 12 & 8 & 2 & 4 & 4 & 9 & 3 & 0 & 9 & 9 & 12 & 10 \\
8 & 10 & 6 & 4 & 5 & 4 & 7 & 0 & 0 & 9 & & 10 \\
\hline
\end{tabular}

IAA: indol Acetic acid by $\mu \mathrm{g} / \mathrm{ml}$

SA: salysalic acid by $\mu \mathrm{g} / \mathrm{ml}$

Zns: Zink solubilization zone by $\mathrm{mm}$

Ps: phosphate solubilization zone by $\mathrm{mm}$

PNF: putative N2-fixation 5 subculture in $\mathrm{N}$-free medium. 
Table 3. Effect of $p H$, temperature and salt content on growth of strains (six strains).

\begin{tabular}{lllllllll}
\hline \multirow{2}{*}{ Strain } & \multicolumn{10}{c}{$\mathbf{p H ~ 7 . 0}$} & \multicolumn{10}{c}{$\mathbf{p H ~ 1 0 . 0}$} \\
\cline { 2 - 10 } No. & $\mathbf{3 0}{ }^{\circ} \mathbf{C}$ & & $\mathbf{5 0}{ }^{\circ} \mathbf{C}$ & \multicolumn{3}{c}{$\mathbf{3 0}{ }^{\circ} \mathbf{C}$} & \multicolumn{3}{c}{$\mathbf{5 0}{ }^{\circ} \mathbf{C}$} \\
\cline { 2 - 10 } & $-\mathbf{s}$ & $+\mathbf{s}$ & $-\mathbf{s}$ & $+\mathbf{s}$ & $\mathbf{- s}$ & $+\mathbf{s}$ & $\mathbf{- s}$ & $+\mathbf{s}$ \\
\hline $\mathrm{S}_{1}$ & + & - & + & - & + & - & + & - \\
$\mathrm{S}_{2}$ & + & - & + & - & + & - & + & - \\
$\mathrm{S}_{3}$ & + & - & + & - & + & - & + & - \\
$\mathrm{S}_{4}$ & + & + & + & + & + & + & + & + \\
$\mathrm{S}_{5}$ & + & + & + & + & + & + & + & + \\
$\mathrm{S}_{6}$ & + & + & + & - & + & + & + & - \\
\hline
\end{tabular}

- $+\mathrm{S}:+15 \%$ salt

- -S: no salt

- Incubation period $72 \mathrm{~h}$

- Three replicates were used for each treatment.

All isolates, as presented in the table (1) were described as facultative oligotrophs.

Some selected isolates were grown on silica gel nutrient broth (SGNB) to avoid the presence of any soluble organic carbon may found in agar when used as solidifying agent and, ensure whether the isolate is obligate or facultative oligotrophs.

The capability of isolates to produce some plant growth promoters was also determined, because in poor soils, such as in present case, it may provide plants with such compounds. Sixty isolates, out of the total, were capable to produce IAA in detectable amounts ( 5 to $15 \mu \mathrm{g} / \mathrm{ml}$ ). Five isolates only produce salyselic acid in appreciable amounts $(>100 \mu \mathrm{g} / \mathrm{ml})$, thirty five produce less than $100 \mu \mathrm{g} / \mathrm{ml}$ and the rest (72 isolates) cannot produce the compound. Zink solubilization due to acids production by different isolates was also determined. Sum of

Indolacetic acid production

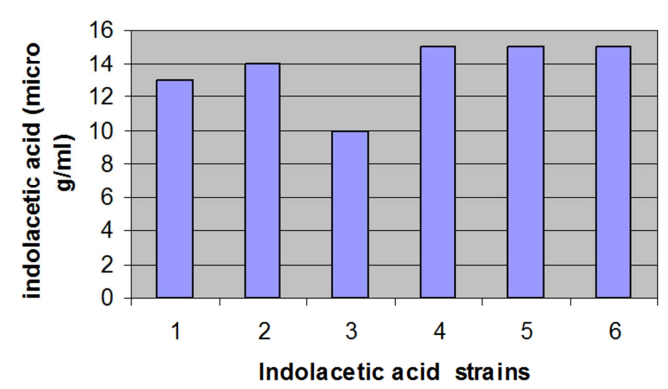

Zink soluilization

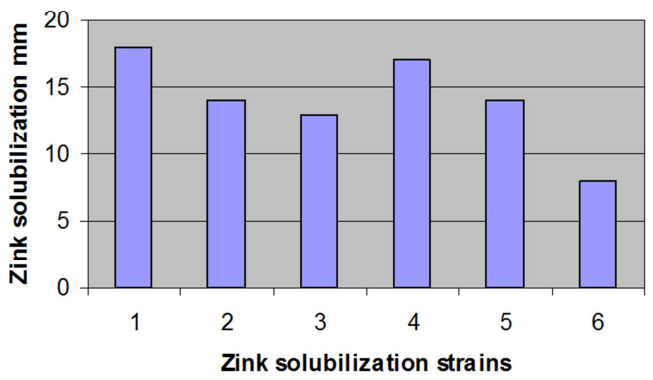

fifty five isolates showed detectable clear zone (5 to $10 \mathrm{~mm}$ diameter) and the rest gave no clear zone. The picture was similar in case of phosphate solubilization where fifty two isolates produce pronounced clear zone (5 -10 mm diameter). Deveci et al., [25], stated that the production of acids by mesophilic and extremely thermophilic oligotrophic bacteria display superior kinetics in dissolution of zink. While Zeng et al., [26], isolated a moderately thermophilic acidophelic oligotrophic iron oxidizing bacterium.

The ability of different isolates to grow on $\mathrm{N}$-freee medium (putative $\mathrm{N}_{2}$ fixers) was also examined (oligonitrotrophic) in suitable liquid culture medium. The isolate capable of growing in medium free of any $\mathrm{N}$-source for five successive subculture was considered as putative $\mathrm{N}_{2}$ fixer whether the fixation was via $\mathrm{N}_{2}$-ase or by scavenging nitrogen from the surroundings. It is possible to call this organism as "oligocarbonitrotrophic" organism because it can grow in low carbon-free nitrogen environment. Satio et al., [27], Eleven isolates of slow growing $\mathrm{N}_{2}$-fixing oligotrophic bacteria from soil. Were obtained Horikawa et al., [11], stated that $\mathrm{N}_{2}$-fixation by aquatic oligotrophic bacteria is an important biological process that add new nitrogen to oceans. Studying ocean microbiology, also Fong et al., [12], revealed high abundance of several oligotrophic $\mathrm{N}_{2}$-fixing cyanobacteria. Out of the 112 isolates tested, fourty seven were able to obtain nitrogen. Nitrogen fixation efficiency as classically done had employed here (mg N fixed/g carbon consumed). Fourten isolates only were $\mathrm{G}^{+}(12.5 \%)$, most were motile 107 (95.5\%), and spore formers were 89 (79\%). Colony shape was mostly circular or irregular. Data obtained by many researches were to somewhat similar [28-30], [1].

salysalic acid production

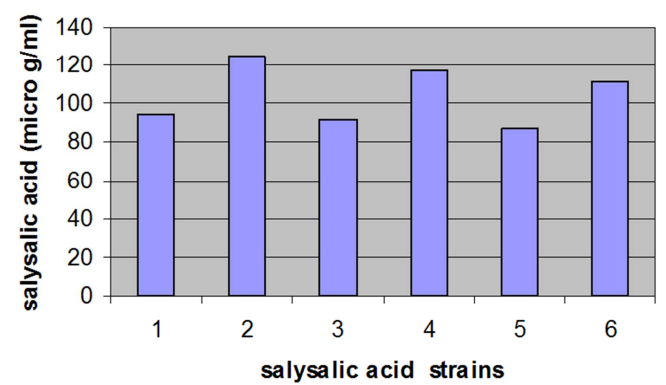

phosphate soluilization

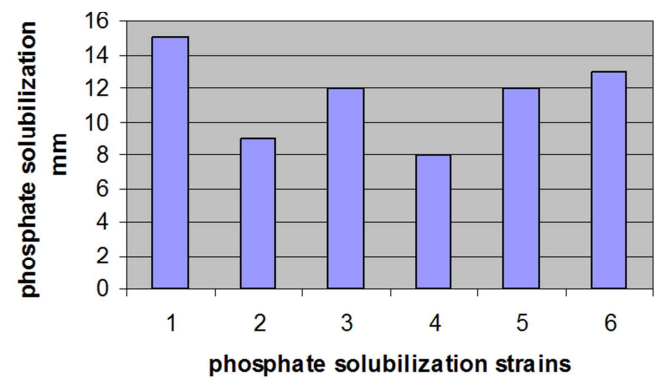

Fig. 1. Some activities of isolates putative oligotrophic bacteria. 


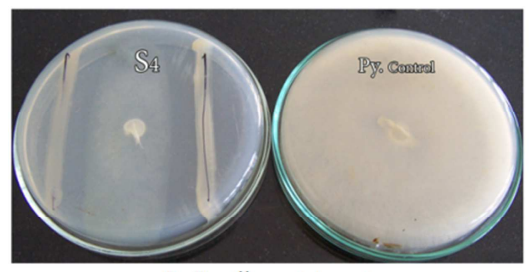

$\mathrm{S}_{4}$ Bacillus spizizenni

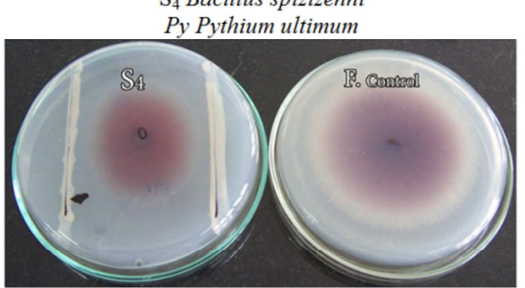

$\mathrm{S}_{4}$ Bacillus spizizenni

F Fusarium oxysprium

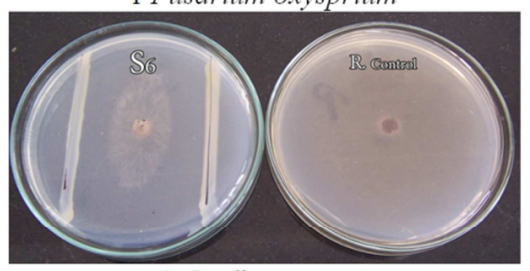

$\mathrm{S}_{4}$ Bacillus spizizenni

$\mathrm{R}$ Rhizoctonia solani

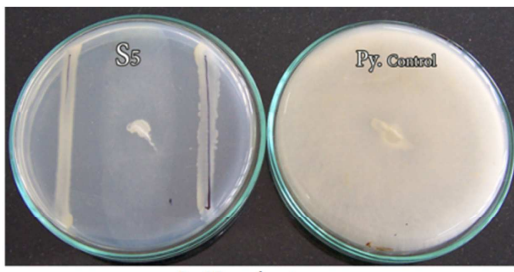

$\mathrm{S}_{5}$ Naxobaxter sp.

Py Pythium ultimum

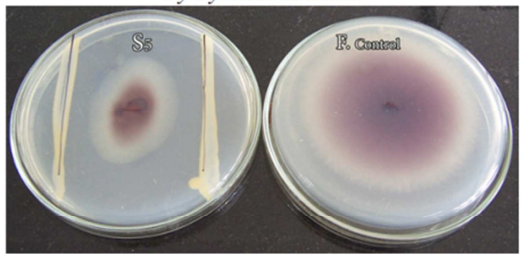

$\mathrm{S}_{5}$ Naxobaxter sp.

F Fusarium oxysprium

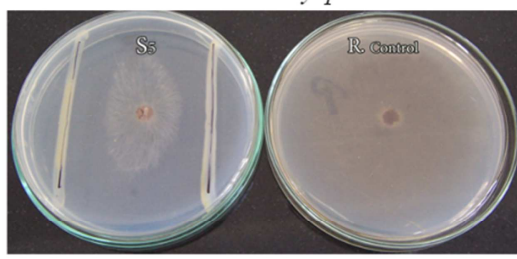

$\mathrm{S}_{5}$ Naxobaxter sp.

R Rhizoctonia solani

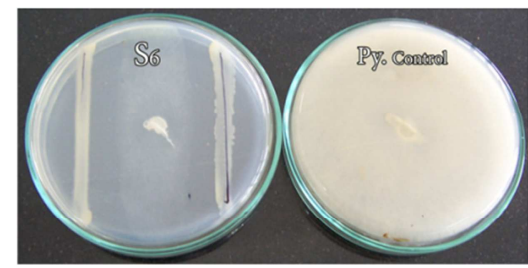

$S_{6}$ Bacillus megaterium

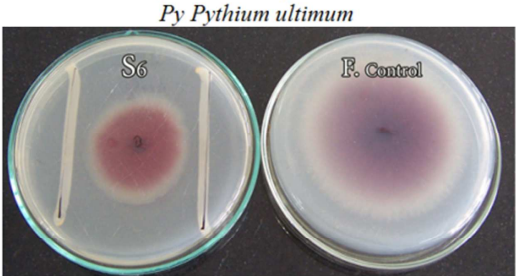

$S_{6}$ Bacillus megaterium

F Fusarium oxysprium

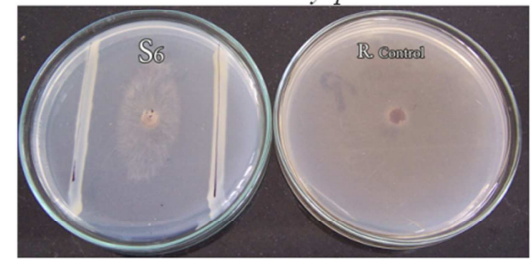

$S_{6}$ Bacillus megaterium

$\mathrm{R}$ Rhizoctonia solani

Fig. 2. Inhibition zone produced from the selective six isolates against the tested pathogenic fungi.

The six isolates characterized by high efficiency in different activities examined (IAA, S. A Zn, P, and $\mathrm{N}_{2}$-fixation) were tested if they are obligate or facultative oligotrophs by growing on silica gel nutrient broth (SGNB) with the different dilutions. Worthmentioning, all isolates were facultative not obligate oligotrophs as they grow well on complete as well as on silica gel medium. [31], isolated oligotrophic actinomycetes on silica gel medium. While [1], sated that the oligotrophic isolates from soil is very limited and ambiguous. [2], obtained a facultative oligotrophs with higher concentration of dissolved organic carbon. In contrast [3], found that denitrifying bacteria isolates were DNB organisms of the oligotrophic type did not show appreciable growth on the NB medium. Recent [4], isolated an obligate oligotrophic bacterium from biological soil crust.

The selected six isolates showed high potency against some economically important pathogenic fungi causing, damping-off disease (Pythium ultimum, Fusarium oxysprium and Rhizoctonia solani) (Fig 1 and 2). All the six isolates showed an inhibitory (in vitro) against the test fungi. These six isolates were identified and involved on anther proceeding study.

\section{Conclusion}

From these results it could be concluded that a total one hundred and twelve bacterial isolates were isolated from eight different soil sites using different dilutions of NB medium. Ninety eight of them were obtained from NB/ 1000 and fourteen were obtained from NB/ 10000. All isolates were proved to elucidate the phenomenon of oligotrophy. The results indicated that all isolates are facultative oligotrophs as they grew on silica gel NB medium deprived of any source of carbon as well as on complete NB medium. All isolates examined were oxidase and catalase positive and cannot ferment lactose. Most of them were Gram-positive, motile, spore formers, rods. Eleven isolates could produce IAA in considerable amounts $(15 \mu \mathrm{g} / \mathrm{ml})$, and five isolates were capable to produce salicylic acid in high amounts (>100 $\mu \mathrm{g}-1 / \mathrm{ml}-1)$. Nine isolates solubilized phosphate and zinc as indicated by clear zone $(>10$ mm diameter), surrounding colonies on the media containing tri calcium phosphate and zinc oxide, respectively. Forty-seven isolates were able to fix nitrogen in medium deprived completely of $\mathrm{N}$-source and they characterized as oligonitrotrophic isolates. In addition, some isolates were positive for chitinase and cellulase production and were able to antagonize some plant pathogenic fungi such $P y$. altimum, $R$. solani, and $F$. oxiysporium. Finally, these results could enable us to develop a new superior oligotrophic inocula as plant growth promoters suitable for new reclaimed soils under adverse conditions. However, further work under study to evaluate the effectiveness of these isolates under field conditions.

\section{References}

[1] Schut, J. T., Qi, X. and P. Stam, (1997). Association between relationship measures based on AFLP markers, pedigree data and morphological traits in barley. Theor. appl. Genet. 95: $1161-1168$

[2] Petrovic, O., Gajin, S., Matavulj, M., Radnovic, D. and Z. Svircev, (1998). Microbiological investigation of water quality of surface waters. Institute of biology, Faculty of natural sciences, University of Novi Sad, Novi Sad (In Serbian). 
[3] Hashimoto, T., Whang, K. S. and K. Nagaoka, (2006). A quantitative evaluation and phylogenetic characterization of oligotrophic denitrifying bacteria harbored in subsurface upland soil using improved culturability. Biol. Fertil, Soils. 42: 179-185.

[4] Pan, H., Ming, C. Z., Mei, Z. X., Yong, M. S., Ling, Q. S. and W. Fang, (2007). A study on an oligotrophic bacteria and its ecological characteristics in an arid desert area. Sci. China. Ser. D-Earth Sci. 50: 128-134.

[5] Zehr, J. P. Edward, J. Carpenter, J. and A. Tracy, (2000). New perspectives on nitrogen-fixing microorganisms in tropical and subtropical oceans. Trends in Microbiology. 8: (2) 68- 73.

[6] Bo-Song, and G. Laura, (2007). Identification and characterization of bacterial isolates from the Mir space station. Microbiological Research. 160: 111-117.

[7] Liu, D. W., Zeng, R. J. and I. Angelidaki, (2008). Enrichment and adaptation of extreme-thermophilic $\left(70^{\circ} \mathrm{C}\right)$ hydrogen producing bacteria to organic household solid waste by repeated batch cultivation. International journal of hydrogen energy 33: 6492-6497.

[8] Prakash, B., Vidyasagar, M., Madhukumar, M. S., Muralikrishna, G. and K. Sreeramulu, (2009). Production, purification, and characterization of two extremely halotolerant, thermostable, and alkali-stable a-amylases from Chromohalobacter sp. TVSP 101. Process Biochemistry 44: 210-215.

[9] Avci, A. and S. Do"nmez, (2009). A novel thermophilic anaerobic bacteria producing cyclodextrin glycosyltransferase. Process Biochemistry 44: 36-42.

[10] Albino, U., Saridakis, D. P., Ferreira, M. C., Hungria, M., Vinusea, P. and G. Andrade, (2006). High diversity of diazotrophic bacteria associated with the carnivorous plant Drosera villosa var. villosa growing in oligotrophic habitats in Brazil. Plant Soil. 287: 199-207.

[11] Horikawa, K., Minagawa, M., Kato, Y., Murayama, M., S. Nagao, (2006). $\mathrm{N}_{2}$ fixation variability in the oligotrophic Sulu Sea, western equatorial Pacific region over the past 83. Journal of Oceanography. 62 (4): 427-439.

[12] Fong, A. A., Karl, D. M., Lukas, R., Letelier, R., Zehr, J. P., and M. J. Church, (2008). Nitrogen fixation in an anticyclonic eddy in the oligotrophic North Pacific Ocean. The ISME Journal. 2: 663-676.

[13] Baron, E. J. Peterson, L. R. and S. M. Finegold, (1994). Bailey \& Scott's Diagnostic Microbiology, 9th Edition. Mosby-Year Book, Inc. St. Louis, USA. 14: 168-188.

[14] Rodriguez, H., Gonzalez, T., Igoire, I. and Y. Bashan, (2004). Gluconic acid production and phosphate solubilization by the plant growth promoting bacterium Azospirillum spp. Naturwissneschaften 91: 552-555.

[15] Saravanan, V. S., Subramoniam, S. R. and S. A. Raj, (2003). Assessing in vitro solubilization potential of different zinc solubilizing bacterial (ZSB) isolates. Barzilian Journal of Microbiology 34, 121-125.

[16] Loper, J. E. and M. N. Schroth, (1986). Influence of bacterial sources of indole-3-acetic acid on root elongation of sugar beet. Phytopathology 76: 386-389.
[17] Meyer, J. M. and M. A. Abdallah, (1987). The fluorescent pigment of Pseudomonas fluorescens biosynthesis, purification and physicochemical properties. Journal of General Microbiology 107: 319-328.

[18] Andro, T., Chambost, J. P., Kotoujansky, A., Cattaneo, J., Bertheau, Y., Barras, F. van Gijsegem, F. and A. Coleno, (1984). Mutants of Erwinia chrysanthemi defective in secretion of pectinase and cellulase. Journal of Bacteriology 160: 1199-1203.

[19] Renwick, A., Campbell, R. and S. Coe, (1991). Assessment of in vivo screening systems for potential biocontrol agents of Gaeumannomyces graminis. Plant Pathology 40: 524-532.

[20] Cattelan, A. J., Hartel, P. G. and J. J. Fuhraman, (1999). Screening for plant growth-promoting substances to promote early soybean growth. Soil Science Society of America Journal 63: 1670-1680.

[21] Koch, E. (1997). Screening of rhizobacteria for antagonistic activity against Pythium ultimum on cucumber and kale. Journal of plant diseases and production 104, 353-361.

[22] Parkinson, S. M., Wainwright. M. and K. Killham, (1989). Observations on oligotrophic growth of fungi on silica gel. Mycol. Res. 93: 529-534.

[23] Ohta, H. and T. Hattori, (1980). Bacteria sensitive to nutrient broth medium in terrestrial environments. Soil Sci. Plant Nutr. 26: 99-107.

[24] AI-Falih, A. M. (2003). Effect of silicon compounds on oligotrophic soil bacteria. Saudi. J. Biol. Sci. 10 (2): 131-137.

[25] Deveci, H., Jordan, M. A., Powwell, N. and I. Alp, (2008). Effect of salinity and acidity on bioleaching activity of mesophilic and extremely thermophilic bacteria. Metals Society of China. 18: (3) 714-721.

[26] Zeng, W. M., Wu, C. B., Zhang, R. B., Hu, G. Z., Gu, G. H. and H. B, Zhou, (2009). Isolation and identification of moderately thermophilic acidophilic iron-oxidizing bacterium and its bioleaching characterization. Nonferrous Met. Soc. China 19: 222-227.

[27] Saito, A., Mitsui, H., Hattori, R., Minamisawa, K. and T. Hattori, (1998). Slow-growing and oligotrophic soil bacteria phylogenetically close Bryhizobium japanicum. FEMS Microbial Eco. 25: 227-286.

[28] Whang, K. and T. Hattori, (1988). Oligotrophic bacteria from rendzina forest soil. Antonie van Leeuwenhoek 54: 19-36.

[29] Lee, J. W. and K. S. Whang, (2004). Isolation and Characteristics of Alkaline Protease Producing Oligotrophic Bacteria from Serpentinite Soil. International Symposium on Identification and Use of Microbial Resources for Sustainable Agriculture. Mokwon University, Korea.

[30] Ishii, H., Nishijimab, M., and T. Abe, (2004). Characterization of degradation process of cyanobacterial hepatotoxins by a gram-negative aerobic bacterium. Water Research 38: 2667 2676.

[31] AL-Turk, I. M. (1990). In vitro studies on Streptomyces in relation to their role in mineral cycling in soil. Ph.D Thesis, Sheffield University. 